\title{
DELITOS CONTRA LA ADMINISTRACIÓN DE JUSTICIA. UNA INTRODUCCIÓN A LA REGULACIÓN DE ALGUNAS FIGURAS EN EL CÓDIGO PENAL ESPAÑOL
}

\author{
Miguel POLAINO-ORTS*
}

\begin{abstract}
Resumen
En este estudio se sistematiza y analiza críticamente la regulación de los delitos contenidos en los numerales 1 a 4 del Código Penal español en todas sus modalidades: prevaricación judicial, omisión de deberes de impedir delitos o promover su persecución, encubrimiento y realización arbitraria del propio derecho. Se trata de figuras delictivas relacionadas con el desempeño de la función judicial por los jueces, el entorpecimiento de dicha función por parte de un tercero ajeno al sistema de justicia, el incorrecto entendimiento de la idea de justicia por los particulares que pretenden tomarse la justicia por su mano o burlando la correcta impartición de justicia. La incriminación de dichos ilícitos penales tiene por finalidad proteger el bien jurídico "Administración de Justicia", concepto que es analizado desde el punto de vista orgánico, estructural, funcional y de su control político.
\end{abstract}

Palabras clave: Administración de Justicia - Sistema judicial - Conducta típica - Imputación - Prevaricación - Encubrimiento - Sentencia injusta.

\begin{abstract}
This study systematizes and critically analyzes the regulation of the crimes contained in Articles 1 to 4 of the Spanish Criminal Code in all its forms: judicial corruption, failure to comply with the duty to prevent crimes or promote their prosecution, aiding and abetting (concealment) and arbitrary use of the law. These are offences related to the performance of the judicial function by the judges, the obstruction of said function by a third person not related to the justice system, the wrong understanding of the idea of justice by private persons who attempt to take justice into their own hands or disturb the proper administration of justice. The purpose of prosecuting the referred offences is to protect the legal interest "the Administration of Justice", a concept that is analyzed from an organic, structural and functional viewpoint and its political control.
\end{abstract}

Key words: Administration of Justice - Judicial System - Typical Behavior

- Accusation - Corruption - Concealment - Unfair Judgment.

\footnotetext{
* Doctor Iuris por la Universidad de Sevilla, España y Profesor de la misma universidad. Profesor Visitante en la Universidad Peruana Los Andes. Profesor Honorario de la Universidad de Huánuco y de la Universidad Inca Garcilaso de la Vega.
} 
Miguel Polaino-Orts - Delitos contra la administración de justicia. Una introducción a la regulación de algunas figuras en el Código Penal Español

\section{Sumario}

1. Introducción a los delitos contra la Administración de Justicia: bien jurídico, sistemática y contenido del Título XX. 2. Prevaricación Judicial: 2.1. Prevaricación dolosa (art. 446). 2.2. Prevaricación imprudente (art. 447). 2.3. Negativa de juzgamiento (art. 448). 2.4. Retardo malicioso en la Administración de Justicia (art. 449). 3. Omisión del deber de impedir delitos o de promover su persecución (art. 450). 4. Encubrimiento. 4.1. Encubrimiento objetivo o real (art. 451.1 y 2). 4.2. Encubrimiento subjetivo o personal (art. 451.3). 5. Realización arbitraria del propio derecho (art. 455).

\section{INTRODUCCIÓN A LOS DELITOS CONTRA LA ADMINISTRACIÓN DE JUSTICIA: BIEN JURÍDICO, SISTEMÁTICA Y CONTENIDO DEL TÍTULO XX}

El Título XX del Libro II del CP español de 1995 se destina a la incriminación de los Delitos contra la Administración de Justicia. Esta rúbrica legal incorpora, según la doctrina mayoritaria, el bien jurídico protegido en la presente materia: la Administración de Justicia. Sin embargo, el CP se limita a incriminar una serie de figuras delictivas relacionadas con la impartición de Justicia, pero no ofrece, en cambio, una definición sobre lo que haya de entenderse por Administración de Justicia. Este concepto puede analizarse desde varios puntos de vista:

- Desde la óptica orgánica, Administración de Justicia alude al conjunto de órganos y tribunales, unipersonales o colegiados, insertos en el organigrama judicial: se trata, pues, del conjunto de jueces y magistrados, concebidos en su función jurisdiccional.

- Desde el punto de vista estructural, se menciona la composición y estructura jerárquica del sistema judicial.

- Desde el prisma funcional, el término se refiere a la distribución competencial de cada órgano judicial y, sobre todo, a la impartición stricto sensu de la Justicia: la función judicial viene expresamente determinada en la Constitución, cuyo art. 117.3 cifra dicha función en los cometidos de "juzgar y hacer ejecutar lo juzgado".

- Finalmente, desde el punto de vista del control político, el concepto alude al control y gestión de la actividad judicial (regidas en España por el Consejo General del Poder Judicial, que es el máximo órgano de gobierno de los jueces y magistrados).

Pues bien, los delitos previstos en el presente título $X X$ se relacionan, de una u otra manera, con alguno de estos aspectos de la Administración de 
Miguel Polaino-Orts - Delitos contra la administración de justicia.

Una introducción a la regulación de algunas figuras en el Código Penal Español

Justicia, ya sea en relación al desempeño de la función judicial por los propios jueces o magistrados (así, por ejemplo, el delito de prevaricación judicial, que sanciona la más grave infracción del deber judicial de dictar sentencia justa), ya sea referido al entorpecimiento de dicha función por parte de un tercero ajeno al sistema de justicia (v.gr. el delito de obstrucción a la justicia), ya sea en un incorrecto entendimiento sui generis de la idea de Justicia por parte del particular que pretende tomarse la justicia por su mano (así, en el delito de realización arbitraria del propio derecho), ya sea burlando de manera mendaz la correcta impartición de Justicia (como sucede en los delitos de falso testimonio y de acusación o denuncia falsas).

En un intento de sistematizar los delitos incriminados en los nueve capítulos de que se compone el presente título, podemos esquematizarlos de la siguiente manera:

1) Prevaricación judicial, que a su vez incorpora varios tipos de delito
a) Prevaricación dolosa (art. 446)
b) Prevaricación imprudente (art. 447)
c) Negativa de juzgamiento (art. 448)
d) Retardo malicioso en la Administración de Justicia (art. 449)

2) Omisión de los deberes de impedir delitos o de promover su persecución (art. 450)

3) Encubrimiento, que engloba -además de varias reglas de exención y de ampliación de pena- dos figuras de delito:
a) Encubrimiento real (art. 451.1 y 2)
b) Favorecimiento personal (art. 451.3)
4) Realización arbitraria del propio derecho (art. 455)
5) Acusación y denuncia falsas (art. 456)
6) Simulación de delito (art. 457)

7) Falso testimonio, que engloba varios tipos diversos:

a) Falso testimonio en causa judicial (art. 458)

b) Falso testimonio de peritos o intérpretes (art. 459)

c) Falso testimonio mediante reticencias, inexactitudes o silencios (art. 460)

d) Presentación de testigos falsos o peritos o intérpretes mendaces (art. 461)

8) Obstrucción a la justicia (arts. 463 a 466) y deslealtad profesional (art. 467) 
Miguel Polaino-Orts - Delitos contra la administración de justicia.

Una introducción a la regulación de algunas figuras en el Código Penal Español

9) Quebrantamiento de condena o medida cautelar (art. 468) y evasión de presos (arts. 469 y 470 )

10) Delitos contra la Administración de Justicia de la Corte Penal Internacional (art. 471 bis).

En este estudio de hoy nos vamos a referir a los delitos contenidos en los números 1 a 4, con todas sus modalidades: prevaricación judicial, omisión de deberes de impedir delitos o promover su persecución, encubrimiento y realización arbitraria del propio derecho, cuyas regulaciones en el Código penal español vigente serán expuestas críticamente en las páginas siguientes, sin perjuicio de un estudio ulterior donde se complete el análisis crítico de las figuras delictivas contra la Administración de Justicia. Entremos, pues, sin más demora, en materia.

\section{PREVARICACIÓN JUDICIAL}

El Capítulo I del Título XX incrimina, bajo la rúbrica común "De la prevaricación", cuatro figuras delictivas, a saber: 1) prevaricación dolosa (art. 446); 2) prevaricación imprudente (art. 447); 3) negativa de juzgamiento (art. 448) y 4) retardo malicioso en la Administración de Justicia (art. 449).

\subsection{Prevaricación dolosa (art. 446)}

La primera figura de delito contra la Administración de Justicia es el tipo básico de prevaricación judicial, prevista en el art. 446:

“El Juez o Magistrado que, a sabiendas, dictare sentencia o resolución injusta será castigado:

1. Con la pena de prisión de uno a cuatro años si se trata de sentencia injusta contra el reo en causa criminal por delito y la sentencia no hubiera llegado a ejecutarse, y con la misma pena en su mitad superior y multa de doce a veinticuatro meses si se ha ejecutado. En ambos casos se impondrá, además, la pena de inhabilitación absoluta por tiempo de diez a veinte años.

2. Con la pena de multa de seis a doce meses e inhabilitación especial para empleo o cargo público por tiempo de seis a diez años, si se tratara de una sentencia injusta contra el reo dictada en proceso por falta.

3. Con la pena de multa de doce a veinticuatro meses e inhabilitación especial para empleo o cargo público por tiempo de diez a veinte años, cuando dictara cualquier otra sentencia o resolución injustas". 
Miguel Polaino-Orts - Delitos contra la administración de justicia.

Una introducción a la regulación de algunas figuras en el Código Penal Español

La conducta típica consiste en dictar una sentencia o resolución injusta a sabiendas de su injusticia. Con ello, se infringe el deber esencial de todo juez y magistrado, a saber: resolver, con criterios de justicia, un caso problemático que se le presenta aplicando las normas jurídicas vigentes al supuesto problemático, esto es: hacer justicia mediante resoluciones judiciales. De esa forma, el juzgador no solo es un sujeto imprescindible en la materialización de la justicia, sino que de él (del correcto ejercicio de su cometido) depende la confianza de los ciudadanos en el entero sistema judicial. En consecuencia, el juez o magistrado que, a sabiendas, dicta una sentencia o resolución injusta no solo menoscaba o lesiona el legítimo interés del juzgando, sino que quebranta el normal funcionamiento de la Administración de Justicia, defraudando de tal modo la expectativa que la Sociedad había depositado en él como garante de la impartición de Justicia.

Bien jurídico es la Administración de Justicia en su aspecto funcional, esto es: el correcto desempeño del cometido de impartición de Justicia. Dicho cometido compete, exclusivamente, a sujetos especiales revestidos de una concreta cualidad fundante: ser el funcionario público a quien se encomienda dicha competencia (juez o magistrado). Se trata, pues, de un delito especial, y no de un delito común: sujeto activo de la prevaricación judicial no puede ser cualquiera, sino exclusivamente quien tiene autoridad y competencia para dictar la resolución o sentencia en el caso concreto, y ello con independencia de que sea o no el titular del órgano jurisdiccional o se halle transitoriamente en una situación administrativa de interinidad (juez substituto, etc.) o encargado temporalmente de dicho cargo aunque no sea juez de carrera, sino que haya accedido al cargo por el llamado cuarto turno, como jurista de reconocido prestigio profesional.

El verbo típico dictar (una sentencia o resolución) equivale a pronunciar o emitir dicho pronunciamiento injusto. La distinción entre acción y omisión es puramente fenomenológica, lo cual es irrelevante desde el punto de vista jurídico: normativamente es indiferente que el delito se realice por acción o por omisión (impropia: comisión por omisión), pues lo que interesa es que se vulnere la idea de Justicia en la solución de un caso concreto. Por ello, lo mismo prevarica quien dicta positiva o activamente la resolución injusta que quien omite analizar aspectos esenciales del caso, propiciando de tal modo una solución injusta -prevaricatoria- al problema.

Cuestión discutida es la extensión de la imputación por prevaricación a los jueces o magistrados que, en los tribunales colegiados, se adhieren y firman 
Miguel Polaino-Orts - Delitos contra la administración de justicia.

Una introducción a la regulación de algunas figuras en el Código Penal Español

como suya la resolución del Magistrado ponente. Aunque materialmente no hayan redactado la resolución, formalmente les corresponde en absoluto y, en consecuencia, también ellos dictan una sentencia injusta. Responderá, pues, por prevaricación dolosa en comisión por omisión en el juez o magistrado que no se opone, en el seno del tribunal colegiado, a la sentencia o resolución del magistrado ponente, avalándola con su firma. En este sentido, la doctrina exige que concurran en el magistrado que se adhiere, a más del dolo (es decir: conocimiento de la ilegalidad de la resolución), el elemento subjetivo a sabiendas, que -en tanto presupuesto cognitivo- es personal e intransferible, de forma que la simple adjunción de firma en la sentencia del ponente no confiere tal elemento subjetivo a quien se adhiere (Polaino Navarrete).

Ejemplo de prevaricación por acción: el Magistrado A, reconociendo en caso que ha de juzgar a B -un antiguo enemigo-, dicta a sabiendas una sentencia injusta condenando al inocente.

Ejemplo de prevaricación por omisión de algún aspecto fundamental: el Magistrado A, que ha de juzgar a B, dicta a sabiendas la sentencia injusta condenatoria, omitiendo en los fundamentos de Derecho la evidencia de que $B$ no se hallaba en el lugar de los hechos sino de viaje en el extranjero; $u$ omitiendo analizar la evidencia de que la víctima murió por un infarto y no por muerte violenta, etc.

Ejemplo de prevaricación en comisión por omisión: el Magistrado ponente A1 dicta, a sabiendas de su injusticia, sentencia condenatoria contra B; los Magistrados A2 y A3, conocedores de la injusticia, omiten oponerse a la sentencia y la firman tal como la dicta el ponente. A2 y A3 responden por prevaricación dolosa (en comisión por omisión), exactamente igual que el ponente, pues su deber de garante les obligaba a evitar el resultado lesivo producido.

La sentencia o resolución dictada ha de ser injusta. Con ello, no se alude a la solución meramente equivocada a juicio de otro juzgador, de manera que la sentencia sea susceptible de revisión correctora por parte de un Tribunal de instancia superior. La injusticia a que se refiere el tipo no es una mera discrepancia subjetiva de criterio jurídico. Antes bien, el término injusta significa manifiesta oposición al Derecho: por ello, injusta es la resolución que supone una manifiesta, evidente e incuestionable contradicción con el ordenamiento jurídico (así, entre otras, STS de 14.III.1996; en la doctrina, por todos, González Rus, Gimbernat, García Arán). Por ello, la injusticia 
Miguel Polaino-Orts - Delitos contra la administración de justicia.

Una introducción a la regulación de algunas figuras en el Código Penal Español

relevante para la prevaricación no es de carácter subjetivo (adopción de uno de los varios pareceres sobre una cuestión, aunque otro se repute más acertado o preferible) sino de carácter objetivo (antinormatividad manifiesta y evidente, frontal oposición con el criterio de justicia, abierta vulneración del Derecho).

El tipo exige un elemento subjetivo del injusto de carácter cognitivo: "a sabiendas". Se trata de un presupuesto cognitivo que presupone el dolo y que va más allá de él: no solo se tiene conciencia de los elementos típicos, sino que deliberadamente, a ciencia cierta y sobre seguro, se dicta la sentencia o resolución prevaricatoria. En este sentido, algún autor considera que se exige dolo directo, excluyéndose el dolo eventual (así también, Polaino Navarrete, González Rus, Palomo del Arco; además de la Jurisprudencia mayoritaria: SSTS de 16.V.1992, 20.XI.1995, 4.VII.1996, 24.VI.1998, 3.II.2009...). En cambio, otros autores (como Orts Berenguer) admiten la apreciación de dolo eventual. La cuestión estriba en cómo se interprete el término "a sabiendas": si se interpreta como un elemento subjetivo del injusto que presupone el dolo y va más allá, entonces solo cabe el dolo directo; si se equipara al conocimiento propio del dolo, se abriría la puerta a la aceptación de dolo eventual. En mi opinión, esta segunda postura es la correcta, porque normativamente son indistinguibles el conocimiento de la ilicitud -propio del dolo- y el conocimiento del elemento subjetivo a sabiendas.

No se exige, en cambio, que la sentencia o resolución sean firmes, sino que cabe perfectamente la prevaricación con independencia de la firmeza del pronunciamiento judicial (así, Quintero Olivares).

El art. 446 distingue tres hipótesis de prevaricación judicial dolosa, a saber:

a) Cuando se trate de una sentencia injusta dictada en una causa por delito. En esta primera modalidad el juzgador condena al reo por un delito que no cometió. A efectos de determinación de la pena, el tipo distingue, a su vez, dos supuestos diversos: 1) que la sentencia no haya llegado a ejecutarse; y 2) que ya se haya ejecutado: en el primer caso se impone al juez o magistrado prevaricador la pena de prisión de uno a cuatro años y la de inhabilitación absoluta por un lapso de diez a veinte años; y en el segundo, la pena de prisión en su mitad superior (de dos y medio a cuatro años), la misma pena de inhabilitación (de diez a veinte años) y además multa de doce a veinticuatro meses. 
Miguel Polaino-Orts - Delitos contra la administración de justicia. Una introducción a la regulación de algunas figuras en el Código Penal Español

Esta primera modalidad exige necesariamente que se trate de una sentencia (y no otra resolución, como auto o providencia). Es discutible que haya de entenderse por sentencia no ejecutada o ya ejecutada. Algunos autores (Orts Berenguer, González Rus) consideran la diferencia entre ambas situaciones coincide con el comienzo del cumplimiento de la sentencia: si ya comenzó a cumplirse, se entiende ejecutada; si aun no comenzó, se supone no ejecutada. Este criterio vale, empero, solo para la pena de prisión, pero no para otras penas (como la de multa). Podría pensarse en un segundo criterio: considerar que la sentencia ejecutada es aquella que se cumplió a cabalidad; mientras que la no ejecutada es aquella cuyo cumplimiento no ha comenzado o bien no ha concluido. Esta solución podría explicar más correctamente la diferencia de pena (pues en el segundo caso la injusticia es más notoria), pero en cambio tendría en contra la circunstancia temporal: solo podría imponerse la hipótesis más grave ("sentencia ya ejecutada") cuando hubiera transcurrido el tiempo (eventualmente varios años) de cumplimiento de la sentencia injusta.

b) Cuando se trate de una sentencia injusta dictada en un proceso por falta. En este caso la sentencia condena injustamente al sujeto por una falta, esto es: por una infracción penal de menor gravedad que el delito. En este caso, la pena no es prisión, sino de multa de seis a doce meses y, además, inhabilitación especial (no absoluta) de seis a diez años. En esta hipótesis carece de relevancia si la sentencia se ha ejecutado o no.

c) Cuando se dicte cualquier otra sentencia o resolución injustas. En este supuesto se incluyen sentencias extrapenales (dictadas en un orden jurisdiccional distinto al penal: por ejemplo, por un Juzgado de Familia, o en el ámbito contencioso-administrativo, o laboral, etc.) y cualquier resolución judicial: autos, providencias, etc.

Algún autor (González Rus) incluye también, en esta tercera hipótesis las sentencias penales no incluidas en las dos modalidades anteriores: así, las sentencias dictadas a favor del reo o aquellas en las que no se ventila su responsabilidad criminal. Esta postura es cuestionable, porque -aunque favorezcan al reo- nada excluye que sean sentencias injustas dictadas además en causas por delito o falta, y porque el hecho de que favorezcan al reo -y no se impongan contra él- no puede ser un motivo de exención o de reducción de la responsabilidad del prevaricador. 
Miguel Polaino-Orts - Delitos contra la administración de justicia.

Una introducción a la regulación de algunas figuras en el Código Penal Español

\subsection{Prevaricación imprudente (art. 447)}

El delito de prevaricación culposa o imprudente se prevé en el art. 447 CP:

“El Juez o Magistrado que por imprudencia grave o ignorancia inexcusable dictara sentencia o resolución manifiestamente injusta incurrirá en la pena de inhabilitación especial para empleo o cargo público por tiempo de dos a seis años".

La prevaricación imprudente comparte con la dolosa, además del sujeto activo especial (juez o magistrado), el aspecto objetivo del tipo (dictar una sentencia o resolución manifiestamente injusta: aunque aquí se añade el adverbio manifiestamente, la esencia de la acción es la misma). Sin embargo, ambas difieren en el aspecto subjetivo: mientras que la primera modalidad exige dolo directo y el elemento subjetivo del injusto a sabiendas, la prevaricación culposa, ante la ausencia de dolo, requiere imprudencia grave o ignorancia inexcusable. A diferencia de lo que ocurre en el tipo doloso, en esta modalidad culposa no existe una coincidencia entre lo conocido, lo querido y lo ocurrido, de manera que la resolución o sentencia injusta no es ni conocida ni querida ni perseguida por el juez o magistrado. La imprudencia grave o la ignorancia inexcusable constituyen básicamente supuestos de error de tipo: el juez o magistrado no es que infrinja un deber de cuidado (¡también en el delito doloso se infringe un deber!) sino que yerra sobre un elemento del tipo (el resultado típico) siendo así que ese resultado debió haberse previsto y evitado. Por ello, se imputa prevaricación imprudente al juzgador que carece de un conocimiento actual sobre la injusticia de su resolución, desconocimiento que era evitable y, por tanto, debió haber evitado. En cambio, no se imputa el delito cuando no es previsible, pues lo que no es previsible no es imputable.

Ejemplo: Así, se imputará prevaricación por imprudencia grave al juez que dicte una resolución o sentencia con burda omisión u inobservancia de requisitos o plazos legales, procedimientos, etc. o en supuesto de manifiesto desconocimiento técnico sobre el tema objeto de discusión (ignorancia inexcusable).

Resulta irrelevante el tipo de resolución dictada (sentencia, orden, auto, providencia), así como el orden jurisdiccional en que se dicta (penal, civil, 
Miguel Polaino-Orts - Delitos contra la administración de justicia.

Una introducción a la regulación de algunas figuras en el Código Penal Español

laboral, etc.). La pena correspondiente al prevaricador imprudente es inhabilitación especial para empleo o cargo público por un lapso de tiempo de dos a seis años.

\subsection{Negativa de juzgamiento (art. 448)}

El tipo de negarse a juzgar se incrimina en el art. 448, que dispone lo siguiente:

“El Juez o Magistrado que se negase a juzgar, sin alegar causa legal, o so pretexto de oscuridad, insuficiencia o silencio de la Ley, será castigado con la pena de inhabilitación especial para empleo o cargo público por tiempo de seis meses a cuatro años".

La conducta típica consiste en negarse a juzgar, que es concebida por el legislador como una modalidad de prevaricación. Al incurrir en esta conducta, el sujeto activo (juez o magistrado) incumple el principal y más primario cometido que le compete conforme a su rol: el de dar cabal respuesta jurídica, aplicando una norma vigente a un supuesto problemático que se le presenta. Se trata de una función imprescindible de realización, restablecimiento o materialización de la justicia. Por ello, la actividad de juzgamiento constituye no solo un deber del juzgador sino un derecho del administrado. En ese sentido, con el presente delito se protege el cumplimiento del más fundamental deber de la Administración de Justicia y, al mismo tiempo, el derecho constitucional de los ciudadanos a la tutela judicial efectiva.

La negativa de juzgamiento ha de ser, como cabe suponer, infundada e improcedente. El precepto prevé dos motivos de improcedencia:

- Que el juzgador no alegue causa alguna, esto es: que se niegue a juzgar sin pretextar ni aportar motivo alguno para fundar su negativa.

- So pretexto de oscuridad, insuficiencia o silencio de la ley: en este caso, el juzgador opone como pretexto (esto es: como motivo simulado, irreal y ficticio) una supuesta laguna o defecto legal que le llevaría a abstenerse de cumplir su obligación juzgadora. Lógicamente ha de tratarse de un motivo falso, pues de ser cierto no se daría el tipo. 
Miguel Polaino-Orts - Delitos contra la administración de justicia.

Una introducción a la regulación de algunas figuras en el Código Penal Español

La negativa al juzgamiento puede manifestarse mediante una acción (v.gr. con un acto expreso mediante el cual rehúsa juzgar) o mediante una omisión (v.gr. sin acto expreso, con silencio judicial). Si no consta de algún modo la voluntad de negarse al juzgamiento entonces estaríamos ante el tipo de retardo malicioso en la Administración de Justicia del art. 449. En cambio, si constara un acto expreso denegatorio del derecho a la tutela judicial efectiva nos hallaríamos ante un supuesto de prevaricación (art. 446; así, González Rus). En cambio, concurrirá el delito de negativa a juzgar cuando, constando la voluntad de no juzgar, omita algún acto exigido para el juzgamiento.

Ejemplo: cuando, iniciado el procedimiento, manifiesta su voluntad de no proseguirlo, pretextando falta de claridad en la ley, o resulta inaceptar el ejercicio de acciones $\mathrm{u}$ omite dictar sentencia, etc.

Únicamente cabe la comisión dolosa. La pena prevista es de inhabilitación especial para empleo o cargo público por tiempo de seis meses a cuatro años.

\subsection{Retardo malicioso en la Administración de Justicia (art. 449)}

Una ulterior modalidad de prevaricación lo constituye el retardo malicioso en la Administración de Justicia, castigado en el art. 449, que preceptúa lo siguiente:

“1. En la misma pena señalada en el artículo anterior incurrirá el Juez, Magistrado o Secretario Judicial culpable de retardo malicioso en la Administración de Justicia. Se entenderá por malicioso el retardo provocado para conseguir cualquier finalidad ilegítima.

2. Cuando el retardo sea imputable a funcionario distinto de los mencionados en el apartado anterior, se le impondrá la pena indicada, en su mitad inferior".

La conducta típica consiste en incurrir en retardo malicioso. El inciso $2^{\circ}$. del art. 449.1 define qué se entiende, a estos efectos, por retardo malicioso: el "provocado para conseguir cualquier finalidad ilegítima". De esta definición legal se sigue, por una parte, que se trata de una demora o tardanza intencional, esto es, provocada dolosamente bien por el juez 
Miguel Polaino-Orts - Delitos contra la administración de justicia. Una introducción a la regulación de algunas figuras en el Código Penal Español

bien por el Secretario judicial; queda fuera del concepto $-y$, por tanto, del ámbito del tipo- cualquier retardo imprevisto o fortuito devenido en la Administración de Justicia. Por otra parte, el retardo ha de perseguir un fin espurio. Provocado y finalidad ilegal son, pues, dos requisitos del retardo típico. No se exige, en cambio, que se alcance la ilegalidad pretendida. Si se alcanzara, estaríamos ante un delito diferente (que puede ser desde enriquecimiento hasta la misma prevaricación stricto sensu).

Con todo, algunos autores han interpretado la expresión finalidad ilegítima de manera excesivamente restringida. Así, por ejemplo, QUINTERO OLIVARES menciona, como modalidades de tal finalidad, la de alterar el equilibrio de las partes, favorecer a una parte y/o perjudicar a otra, hacer estéril el objeto de la acción procesal emprendida u obtener un beneficio directo por parte del juez, secretario judicial u otro funcionario. Del mismo modo, GONZÁLEZ Rus considera que queda fuera del ámbito del tipo el retardo debido a simple abandono o negligencia. Desde luego, la simple negligencia queda al margen del tipo de retardo, que exige dolo y perseguir una finalidad ilegal. Pero la finalidad ilegal no ha de consistir necesariamente en un delito, sino en cualquier acto, circunstancia o situación, que perjudique el derecho fundamental a un proceso sin dilaciones indebidas de los ciudadanos. Por ello, cabe el delito de retardo cuando la finalidad no es constitutiva de delito sino solo de infracción administrativa, que -de concurrir- daría lugar a responsabilidad disciplinaria.

Cabe la forma activa y la forma omisiva de realización del tipo: lo mismo se retarda la acción de la justicia con un acto positivo tendente a una finalidad ilegítima que omitiendo imprimir al proceso el ritmo adecuado, ralentizando de ese modo la correcta impartición de justicia.

En el presente delito se amplía el círculo de posibles sujetos activos: al juez o magistrado se une ahora, en el tipo básico (art. 449.1), como sujeto activo idóneo, el Secretario judicial; y en tipo atenuado (art. 449.2), otros funcionarios distintos de los anteriores, que también participan en la Administración de Justicia desempeñando diversos cometidos de diferente entidad (v.gr. fiscales, médicos forenses, oficiales de juzgado, agentes judiciales, auxiliares). Queda excluido, a efectos de la consideración de sujeto activo, en cambio, el retardo ocasionado por las partes del proceso o letrados de las mismas (abogado acusador o abogado defensor). En todo caso, y no obstante la ampliación del círculo de posibles sujetos activos, 
Miguel Polaino-Orts - Delitos contra la administración de justicia.

Una introducción a la regulación de algunas figuras en el Código Penal Español

sigue siendo un delito especial, que no puede ser cometido por cualquiera sino solo por sujetos especialmente revestidos de una cualidad o cargo: el juzgador, el Secretario judicial (que es el fedatario público o notario del proceso que da fe de las actuaciones judiciales evacuadas) $u$ otro funcionario que conforme el personal al servicio de la Administración de Justicia.

Bien jurídico protegido no es tanto la Administración de Justicia en su conjunto, cuanto el derecho fundamental a un proceso sin dilaciones indebidas, consagrado en el art. 24 CE. Desde luego, dicho derecho fundamental es parte esencial del correcto funcionamiento de la Administración de Justicia, junto a otras garantías esenciales del proceso, como la tutela judicial efectiva o el derecho a un juez imparcial. La pena es coincidente con la del tipo de negativa a juzgamiento: inhabilitación especial para empleo o cargo público por un tiempo de seis meses a cuatro años.

\section{OMISIÓN DEL DEBER DE IMPEDIR DELITOS O DE PROMOVER SU PERSECUCIÓN (ART. 450)}

La segunda figura de delito contra la Administración de Justicia (cap. II del Tít. XX) es el tipo de omisión del deber de impedir delitos o del deber de promover la persecución de los mismos, previsto en el art. 450:

\footnotetext{
“1. El que, pudiendo hacerlo con su intervención inmediata y sin riesgo propio o ajeno, no impidiere la comisión de un delito que afecte a las personas en su vida, integridad o salud, libertad o libertad sexual, será castigado con la pena de prisión de seis meses a dos años si el delito fuera contra la vida, y la de multa de seis a veinticuatro meses en los demás casos, salvo que al delito no impedido le correspondiera igual o menor pena, en cuyo caso se impondrá la pena inferior en grado a la de aquél.

2. En las mismas penas incurrirá quien, pudiendo hacerlo, no acuda a la autoridad o a sus agentes para que impidan un delito de los previstos en el apartado anterior y de cuya próxima o actual comisión tenga noticia".
}

Dos son las figuras delictivas previstas en el tipo: de un lado, la omisión del deber de impedir determinados delitos (art. 450.1); de otro del deber de promover la persecución de tales delitos (art. 450.2). Estas modalidades delictivas son ejemplos paradigmáticos de omisión pura o propia. Por ello, guardan una íntima relación y una semejanza estructural con el otro claro 
ejemplo de omisión propia: el delito de omisión del deber de socorro (art. 195). La omisión propia se opone, por definición, a la omisión impura o impropia, más conocida como comisión por omisión. La omisión propia genera una responsabilidad penal más reducida que la de la comisión por omisión: en ésta última, la no evitación del resultado material se equipara a su causación activa cuando el sujeto tenga un específico deber de actuar (esto es: sea garante). El delito de omisión propia, como el tipo del art. 450, consiste también en un no hacer una conducta normativamente debida. Pero, a diferencia del deber de la comisión por omisión, se trata de un deber penal no asumido anteriormente por el sujeto (cualquier sujeto ajeno hasta entonces al hecho), que aflora cuando el sujeto se enfrenta a una situación descrita en la norma: es un deber penal que la norma impone a todo aquél que se halle en la situación descrita en la misma: en el presente caso, el deber de impedir la comisión de un delito determinado o el deber de promover su persecución.

La diferencia normativa y fundamental entre la omisión pura y la comisión por omisión gira en torno al concepto de deber jurídico que infringe el sujeto en cada hipótesis. Dichas diferencias, que definen al tipo de omisión propia (como el delito del art. 450, que nos ocupa) se observan en tres aspectos concretos: a) la naturaleza; b) la titularidad y c) el alcance de ese deber (al respecto, Polaino Navarrete).

a) Naturaleza del deber, que en este caso es un deber llamado de solidaridad mínima (Mindestsolidarität). Se trata de un deber positivo que conmina a toda persona a realizar una conducta positiva de auxilio, salvamento o colaboración en una situación de necesidad o desgracia (Silva Sánchez, Caro John). El deber infringido en cada hipótesis del art. 450 (impedir determinados delitos y promover su persecución o -mejorsu impedimento) es una modalidad del deber de mínima solidaridad: constituyen obligaciones de colaboración ciudadana activa o positiva en la labor de Administración de Justicia (prevención de la delincuencia e identificación de los delincuentes). Este deber de solidaridad se diferencia -en tanto deber positivo- del deber negativo, cuyo contenido consiste en no dañar a los demás (neminem laedere). En la solidaridad mínima no basta con no causar daño sino que exige hacer alguna conducta expresa de salvamento o de colaboración en beneficio de un tercero o de la colectividad. Con ello, el deber de solidaridad persigue la maximización de los bienes, mientras que el deber negativo se encamina a garantizar el máximo de libertad (Jakobs), o lo que es lo mismo: el deber negativo (¡no lesiones a nadie!) preserva la autonomía de la persona, mientras que 
Miguel Polaino-Orts - Delitos contra la administración de justicia.

Una introducción a la regulación de algunas figuras en el Código Penal Español

el deber de solidaridad obliga a la realización de una prestación positiva en favor de terceros o de la comunidad.

b) Titularidad del deber de solidaridad mínima: una segunda característica del art. 450 (y, en general, de los delitos de omisión propia), es que el deber afecta $\mathrm{u}$ obliga a todo el mundo que se encuentre en la situación normativa. No se trata de un deber de garante (que obliga únicamente a concretos sujetos especialmente determinados: por ejemplo, el juez o magistrado respecto de la impartición de justicia, y cuya infracción da lugar a la segunda modalidad de la omisión: la llamada omisión impropia o comisión por omisión), sino de un deber que no exige relación previa alguna entre autor y víctima, ni conducta precedente de peligro al bien jurídico por el autor, sino que otorga una protección erga omnes a un bien jurídico. Del ciudadano -de todo ciudadano- se espera, por el hecho de serlo (esto es: por pertenecer al grupo social) una conducta positiva: la solidaridad mínima (en este caso: de colaboración activa con la justicia). Por ello, los delitos del art. 450 son comunes, y no especiales: porque el titular del deber infringido es cualquier persona, sin requerirse en el autor una cualificación o rol especial, sino únicamente el rol general o común de ciudadano.

c) Alcance del deber: El Derecho penal no exige del ciudadano que sea, siempre y en toda circunstancia, un héroe. No le obliga, por tanto, a lo imposible, sino únicamente a una conducta general y común de mínima solidaridad con los demás. El deber de solidaridad tiene, pues, un límite: no se imputa cualquier resultado material que se derive de una situación peligrosa, sino únicamente no haber realizado una actividad de salvamento o de información, como sucede en los tipos del art. 450, y con siempre que la conducta no realiza fuera posible. La solidaridad mínima no se vincula con la producción de un resultado material, sino con el incumplimiento de un deber básico de mínima solidaridad, de manera que la omisión pura se equipararía a la responsabilidad por delitos de mera actividad (que son aquellos que no exigen para su consumación un resultado material, sino que se consuman por la mera realización de la acción penalmente relevante).

El deber de solidaridad da cuerpo y contenido a la omisión pura; este deber es un producto del Estado social de Derecho: en determinadas circunstancias se espera del ciudadano una determinada prestación que colabore o coadyuve al mantenimiento de la estructura social. Así se entiende el deber de colaboración ciudadana en la prevención de la delincuencia y 
Miguel Polaino-Orts - Delitos contra la administración de justicia.

Una introducción a la regulación de algunas figuras en el Código Penal Español

en la identificación de los delincuentes. Todo ciudadano tiene este deber por el hecho de pertenecer al grupo social. Por ello, el deber de solidaridad resulta del "deber social del ciudadano en una Democracia social" (Welzel). En todo caso, y frente a lo que consideraron pensadores como Stuart Mill y Kant, la solidaridad mínima no es un deber moral, sino un deber propiamente jurídico: "no puede basarse en el amor entre las personas, sino en la exigencia de que cada individuo tiene deberes positivos de acción para el bienestar de la generalidad" (Caro John). Los deberes negativos (no dañar a nadie) no bastan para garantizar la totalidad de las relaciones sociales, sino que -en ocasiones- se requiere de estos deberes positivos que contribuyan mediante la acción positiva al bienestar y al desarrollo del mundo social (Sánchez-Vera).

La infracción del deber ciudadano de colaboración con la justicia da lugar a dos tipos de delito diferentes:

- De un lado, el tipo del art. 450.1, que presupone la omisión -la inobservancia- del deber de impedir determinados delitos mencionados en el precepto: delitos contra la vida (homicidio, asesinato), la integridad física (lesiones), contra la libertad (p.ej., detención ilegal) y contra la libertad sexual (violación, agresiones o abusos sexuales etc.). En estos casos, cuando el ciudadano, con su intervención inmediata, no impida el delito pudiendo hacerlo sin riesgo para él o para otro sujeto, será sancionado con pena de prisión (de seis meses a dos años) si el delito no impedido fuera contra la vida, y con multa de seis a veinticuatro meses en los restantes casos, salvo que el delito no impedido fuera sancionado con pena inferior, en cuyo caso se impondría esta. Lógicamente el sujeto que infringe el deber no es garante: si lo fuera, se le imputaría como coautor, en comisión por omisión, el delito no impedido.

- De otro lado, el tipo del art. 450.2, en el que se infringe el deber de promover la persecución (o mejor: la evitación) de los mencionados delitos. En esta modalidad, se sanciona al sujeto que, pudiendo alertar a autoridad o a agentes de la misma para que eviten el delito, omite hacerlo. La rúbrica del capítulo II del presente título, en el que se inserta el art. 450, habla de "los deberes de impedir delitos o de promover su persecución". Propiamente no se trata aquí de persecución (de los delitos o de los delincuentes), sino de promover o procurar su evitación (por parte de agentes de la autoridad), porque el delito aun no se ha cometido, aunque o se está cometiendo actualmente o es de inminente 
Miguel Polaino-Orts - Delitos contra la administración de justicia.

Una introducción a la regulación de algunas figuras en el Código Penal Español

comisión. Para ello, el tipo exige que el autor omitente "tenga noticia" de la "próxima o actual comisión" del delito. Las penas son idénticas a las de la modalidad anterior, con lo cual se entiende que se aplica una pena mayor si el delito es contra la vida, y más reducida en los demás casos.

El tipo menciona, en los dos apartados, la no evitación de delitos (Rubio Lara). Ergo se entiende, conforme al principio de legalidad, que es atípica la no evitación de faltas, que son infracciones penales de menor entidad que los delitos.

La doctrina mayoritaria niega la posibilidad de apreciar la tentativa en los delitos de omisión propia, como -en general- en los delitos de mera actividad, porque en ellos, al no exigir un resultado material, la mera realización de la conducta (en este caso: la mera omisión de la conducta) ya produce la consumación del tipo. Sin embargo, son conceptualmente imaginables algunos supuestos en los que cabe apreciar la tentativa en la omisión propia.

Ejemplo: un sujeto observa como van a disparar, golpear o violar a alguien en un descampado. Tiene prisa y quiere desentenderse del asunto. Cuando se ausenta apresuradamente del lugar, pasa un policía que toma un gesto involuntario del omitente como una señal de alarma o de llamada de atención, razón por la cual se estaciona el agente y evita el delito. En este caso, si consta el dolo del autor, podría apreciarse delito de omisión del deber de impedir la comisión de delito o de promover su impedimento, en grado de tentativa.

Son imaginables también supuestos de error (v.gr. quien observa a un sujeto golpear a otro por la calle, pero lo toma como una broma entre amigos). Estos casos, se resuelven aplicando las reglas comunes de la doctrina del error (González Rus).

\section{ENCUBRIMIENTO}

El tipo de encubrimiento es previsto en el art. 451, que dispone lo siguiente: 
Miguel Polaino-Orts - Delitos contra la administración de justicia.

Una introducción a la regulación de algunas figuras en el Código Penal Español

"Será castigado con la pena de prisión de seis meses a tres años el que, con conocimiento de la comisión de un delito y sin haber intervenido en el mismo como autor o cómplice, interviniere con posterioridad a su ejecución, de alguno de los modos siguientes:

1. Auxiliando a los autores o cómplices para que se beneficien del provecho, producto o precio del delito, sin ánimo de lucro propio.

2. Ocultando, alterando o inutilizando el cuerpo, los efectos o los instrumentos de un delito, para impedir su descubrimiento.

3. Ayudando a los presuntos responsables de un delito a eludir la investigación de la autoridad o de sus agentes, o a sustraerse a su busca o captura, siempre que concurra alguna de las circunstancias siguientes:

a. Que el hecho encubierto sea constitutivo de traición, homicidio del Rey, de cualquiera de sus ascendientes o descendientes, de la Reina consorte o del consorte de la Reina, del Regente o de algún miembro de la Regencia, o del Príncipe heredero de la Corona, genocidio, delito de lesa humanidad, delito contra las personas y bienes protegidos en caso de conflicto armado, rebelión, terrorismo, homicidio, piratería, trata de seres humanos o tráfico ilegal de órganos.

b. Que el favorecedor haya obrado con abuso de funciones públicas. En este caso se impondrá, además de la pena de privación de libertad, la de inhabilitación especial para empleo o cargo público por tiempo de dos a cuatro años si el delito encubierto fuere menos grave, y la de inhabilitación absoluta por tiempo de seis a doce años si aquél fuera grave".

El encubrimiento constituye una intervención no ejecutiva ex post facto, de manera que se sancionan las llamadas adhesiones post-ejecutivas (Sánchez-Ostiz Gutiérrez). Tradicionalmente se definía el encubrimiento, dentro de la regulación de la autoría y participación, en la Parte general del CP (art. 17 del texto anterior al CP de 1995), y solo se reservaba para la Parte especial una figura específica de encubrimiento con ánimo de lucro como modalidad de receptación (definida por el anterior art. 546 bis a), dentro de los delitos contra la propiedad, como aprovechamiento para sí de los efectos del delito). El CP de 1995 eliminó el encubrimiento de la regulación de la Parte general y lo incluye, en un capítulo propio (el III), como delito autónomo dentro del Título XX dedicado a los delitos contra la Administración de Justicia. 
Miguel Polaino-Orts - Delitos contra la administración de justicia.

Una introducción a la regulación de algunas figuras en el Código Penal Español

Antecedente histórico es la figura romana de la ratificación (ratihabitio), surgida en el ámbito civil como acto complejo que englobaba tanto la convalidación de un negocio jurídico anulable o radicalmente nulo, como la perfección de uno no propiamente anulable pero sí incompleto que, por virtud de la ratihabitio se torna plenamente eficaz (Gutiérrez-Alviz). La estructura de esta figura civil se trasladó posteriormente al ámbito penal, sancionándose el auxilium post delictum de manera separada -y más atenuada- respecto de la ejecución del delito, aunque necesidades técnicas y preventivas determinaron que se incluyera su definición junto a las formas de participación en la Parte general de los códigos españoles (desde el primero, de 1822, y -sobre todo- desde 1848, hasta 1995; al respecto, fundamental, Sánchez-Ostiz; sobre los antecedentes y modalidades de receptación, Gili Pascual, Martos Núñez, Abel Souto).

El art. $451 \mathrm{CP}$ prevé varias modalidades de adhesiones post-ejecutivas para encubrir a posteriori un delito, que constituyen un injusto propio y diferente:

a) Auxilio a autores o cómplices para que se beneficien del provecho, producto o precio del delito, sin ánimo de lucro propio (art. 451.1).

b) Ocultamiento, alteración o inutilización del cuerpo, efectos o instrumentos del delito, para impedir su descubrimiento (art. 451.2).

c) Ayuda a los presuntos responsables del delito para eludir la investigación policial o para sustraerse a su busca o captura, en determinados delitos y bajo concretas circunstancias (art. 451.3).

A las dos primeras figuras se las suele llamar encubrimiento objetivo o real, porque tienen como objeto encubrir el delito o elementos objetivos del mismo (provecho, efectos, instrumentos del delito, etc.). La figura del art. 451.3 integra el encubrimiento subjetivo o personal, en el que se oculta al presunto delincuente para evitar que sea identificado y/o capturado.

Las tres figuras delictivas presentan varios elementos en común: la estructura típica, los sujetos, el bien jurídico, el conocimiento de la comisión del hecho, así como la pena.

- Estructura compleja, conforme a la cual se exige la sucesión secuencial de dos delitos: un primer delito cometido por un sujeto A, y un segundo delito (el de encubrimiento), diferente del primero, pero dependiente de él, que consiste -precisamente- en una acción de auxilio al autor y/o cómplice del primer delito (para que se aprovechen del delito por ellos cometido), o de ocultamiento de instrumentos o pruebas del delito (para impedir su descubrimiento) o de ayuda de los autores y/o cómplices del primer delito (para evitar que sean descubiertos y/o capturados). En esta 
Miguel Polaino-Orts - Delitos contra la administración de justicia. Una introducción a la regulación de algunas figuras en el Código Penal Español

estructura compleja, el primer delito es presupuesto del segundo: si no existe el primero, no puede existir el segundo, pues éste consiste en ocultar objetos o encubrir a los sujetos activos de aquél.

- Sujeto activo (el encubridor) puede cualquier persona, siempre que no sea autor ni cómplice del primer delito a cuyo aprovechamiento auxilia o cuyos objetos o sujetos encubre, porque si lo fuera, no existiría el segundo delito sino que respondería como colaborador necesario del primer delito (siempre que el acto de auxilio se concibiera como acto ejecutivo simultáneo al delito encubierto). El autor (entendido en sentido lato: autor inmediato o único, mediato, coautor, inductor, cooperador necesario ex art. 28) o cómplice (ex art. 29) del primer delito es el destinatario de la acción de auxilio o encubrimiento. Sujeto pasivo del encubrimiento es el Estado, titular de la Administración de Justicia, que es -según el legislador- el bien jurídico protegido en la presente figura.

- Por lo demás, los diferentes modos de encubrimiento exigen el "conocimiento de la comisión del hecho". Algunos autores y la jurisprudencia equiparan este conocimiento con la certeza de que tales sujetos son autores o cómplices del primer delito, o que el instrumento o efectos provienen exactamente de ese delito, lo cual equivale a exigir el dolo directo (Rodríguez Mourullo, Gómez Pavón, STS de 20.VI.1995). Esta postura es, a mi juicio, rechazable: la estructura del tipo, así como la conveniencia político-criminal, hace preferible la aceptación del dolo eventual (lo acepta también Quintero Olivares).

- Finalmente, tienen en común la pena: prisión de seis meses a tres años.

Veamos ahora cada figura por separado.

\subsection{Encubrimiento objetivo o real (art. 451.1 y 2)}

a) La primera modalidad de encubrimiento real es el auxilio prestado, sin ánimo de lucro propio, a autores o cómplices para que se beneficien del provecho, producto o precio del delito por ellos cometido (art. 451.1).

- La acción consiste en el auxilio de autores o cómplices del primer delito. Auxiliar significa prestar una ayuda para alcanzar un determinado fin. El auxilio puede consistir en actos necesarios o no necesarios.

- Se exige un elemento subjetivo del injusto de carácter positivo ("para que se beneficien"). Conforme a esta exigencia, no basta cualquier auxilio, sino que ha de auxiliarse precisamente para aprovechamiento ajeno. Se trata de un elemento de carácter intencional, que configura 
Miguel Polaino-Orts - Delitos contra la administración de justicia. Una introducción a la regulación de algunas figuras en el Código Penal Español

al delito como un tipo intencional de resultado cortado. El beneficio a cuya consecución se auxilia puede ser de cualquier clase, esto es: no ha de ser exclusivamente una ganancia económica (lo exige, en cambio, Gómez Pavón), aunque sea económicamente valuable. Para la consumación del delito de encubrimiento no se requiere, en cambio, que los autores o cómplices del primer delito realmente se lleguen a beneficiar, sino que basta el auxilio con tal fin.

- Además, ha de concurrir un elemento subjetivo del injusto de carácter negativo ("sin ánimo de lucro propio"). Este elemento no sólo refuerza el fin de aprovechamiento ajeno sino que acentúa la separación entre las formas de intervención en el primer delito y la adhesión ulterior, que configura -en el sistema del CP- un injusto diferente.

- Objeto del beneficio al que se auxilia ha de ser el provecho, producto o precio del primer delito, esto es: todo beneficio -económico o noderivado del delito.

b) La segunda modalidad de encubrimiento real es consiste en ocultar, alterar o inutilizar el cuerpo, efectos o instrumentos de un delito, para impedir su descubrimiento (art. 451.2).

- La acción es triplemente alternativa: puede consistir en el ocultamiento, alteración o inutilización de determinados objetos del delito. Tales acciones tienen en común el hecho de dificultar el descubrimiento del delito, lo cual puede tener lugar por una de las modalidades mencionadas en el tipo:

o Ocultar significa hacer desaparecer el cuerpo, efectos o instrumentos del delito previo.

o Alterar equivale a modificar substancialmente la estructura, composición o identidad de tales objetos.

o Inutilizar implica desnaturalizar o hacer inservible en su integridad o parcialmente un objeto hasta hacerlo irreconocible.

- Se exige también aquí un elemento subjetivo del injusto ("para impedir su descubrimiento"). Conforme a este requisito, no es suficiente cualquier acto de ocultamiento, alteración o inutilización sino que ha de actuar precisamente con la finalidad exigida en el tipo: para impedir el descubrimiento del delito. Es, asimismo un elemento intencional, que configura al delito como un tipo intencional de resultado cortado. Al encubridor se le sanciona incluso cuando, no obstante su acto para impedir el descubrimiento del delito, éste termina siendo descubierto. 
Miguel Polaino-Orts - Delitos contra la administración de justicia. Una introducción a la regulación de algunas figuras en el Código Penal Español

- Objeto del ocultamiento, alteración o inutilización son el cuerpo, efectos o instrumentos del delito, que se hacen desaparecer, se modifican substancialmente o se inutilizan desnaturalizándolos en su estructura, composición o integridad:

o Cuerpo del delito (corpus delicti) alude a la cosa en que, o con que, se ha cometido un delito, o en la cual perduran las señales de él (así, la definición contenida en el DRAE). El art. 337 LECr lo define como la persona o cosa objeto del delito, e incluye entre ellos las armas, instrumentos, documentos y efectos de cualquier clase, siempre que tengan relación con el delito, con independencia del lugar donde se hallen (lugar de los hechos, en sus inmediaciones, en poder del reo o en cualquier otra parte $e x$ art. 334 LECr).

o Efectos del delito son aquellas circunstancias o elementos que tienen su causa en el delito.

o Instrumentos son los objetos empleados en la comisión del delito.

\subsection{Encubrimiento subjetivo o personal (art. 451.3)}

El delito de encubrimiento personal castiga la ayuda a los presuntos responsables del delito para eludir la investigación de la autoridad o de sus agentes o para sustraerse a su busca o captura, siempre que concurran determinadas circunstancias, que analizaremos a continuación.

La acción típica consiste en la prestación de ayuda con un fin elusivo. Nada dice el tipo a propósito del tipo, clase o intensidad de la ayuda en cuestión. Se entiende, pues, que puede tratarse de cualquier tipo de ayuda: ya sea logística o material (v.gr. esconder a los sujetos en su propia vivienda), ya sea económica (prestarles una cantidad de dinero para que huyan), etc.; consista en una acción (dar pistas falsas sobre su paradero) o una omisión (omitir decir donde se hallan), etc.

El encubrimiento personal únicamente concurre en determinados supuestos o circunstancias mencionados en el tipo:

- Por un lado, no se da en cualquier delito, sino solo en algunos delitos de especial gravedad contra bienes jurídicos personalísimos (como la vida), contra la humanidad o contra el Estado. Tales delitos son: traición, homicidio del Rey, o de cualquiera de sus ascendientes o descendientes, de la Reina consorte o del consorte de la Reina, del Regente o de algún miembro de la Regencia, o del Príncipe heredero de la Corona, genocidio, delito de lesa humanidad, delito contra las personas y bienes protegidos 
Miguel Polaino-Orts - Delitos contra la administración de justicia.

Una introducción a la regulación de algunas figuras en el Código Penal Español

en caso de conflicto armado, rebelión, terrorismo, homicidio y piratería. A ellos se añade también dos figuras incluidas por obra de la LO 5/2010: trata de seres humanos y tráfico ilegal de órganos.

- En segundo término, se aprecia encubrimiento personal agravado cuando el favorecedor haya obrado con abuso de funciones públicas. En este caso, a la pena de prisión, se añade otras dos penas adicionales y alternativas, que corresponderá imponer según la gravedad del delito: la de inhabilitación absoluta por tiempo de seis a doce años (si el delito fuera grave: $v \cdot g r$. castigado con pena de prisión superior a cinco años: art. 33) o inhabilitación especial para empleo o cargo público por tiempo de dos a cuatro años si el delito encubierto fuere menos grave.

Por lo demás, los arts. 452 a 454 contienen tres reglas generales aplicables a todas las modalidades de encubrimiento:

- La primera es una regla de penalidad, conforme a la cual la pena prevista para el primer delito funge como límite máximo de la pena del encubrimiento: “(e)n ningún caso podrá imponerse pena privativa de libertad que exceda de la señalada al delito encubierto" (art. 452, inciso primero). Además, se establece que si el delito encubierto "estuviera castigado con pena de otra naturaleza, la pena privativa de libertad será sustituida por la de multa de seis a veinticuatro meses, salvo que el delito encubierto tenga asignada pena igual o inferior a ésta, en cuyo caso se impondrá al culpable la pena de aquel delito en su mitad inferior" (art. 452 , inciso segundo).

- La segunda regla es extensiva de la responsabilidad: “(1)as disposiciones de este Capítulo se aplicarán aun cuando el autor del hecho encubierto sea irresponsable o esté personalmente exento de pena" (art. 453).

- Por último, la tercera regla, prevista en el art. 454, es una exención de pena, conocida como encubrimiento entre parientes (impropiamente, porque los cónyuges o novios no son parientes entre sí):

“Están exentos de las penas impuestas a los encubridores los que lo sean de su cónyuge o de persona a quien se hallen ligados de forma estable por análoga relación de afectividad, de sus ascendientes, descendientes, hermanos, por naturaleza, por adopción, o afines en los mismos grados, con la sola excepción de los encubridores que se hallen comprendidos en el supuesto del número 1 del artículo 451". 
Miguel Polaino-Orts - Delitos contra la administración de justicia.

Una introducción a la regulación de algunas figuras en el Código Penal Español

Conforme a esta regla, en los casos del art. 451.2 (ocultamiento, alteración o inutilización del cuerpo, efectos o instrumentos de un delito, para impedir su descubrimiento) y 451.3 (ayuda a los autores o cómplices del delito para eludir la investigación o no ser capturados (art. 451.3) no es punible el encubrimiento. Esta exención penal no opera, en cambio, en el supuesto del art. 451.1 (auxilio a los responsables para que se beneficien del delito).

La regla se aplica en caso de matrimonio válido y vigente, aunque los cónyuges estén separados de hecho. No opera, en cambio, en caso de separación de derecho o de divorcio. La expresión "persona a quien se hallen ligados de forma estable por análoga relación de afectividad" posibilita que la regla se aplique a las parejas de hecho (novios entre sí), aun sin convivencia, incluyendo las parejas del mismo sexo.

Es discutida la naturaleza jurídica de la figura: algunos autores consideran que constituye una excusa absolutoria, que excluye la punibilidad de la conducta típica, antijurídica y culpable (así, González Rus); otros autores consideran que se trata de una causa de exculpación, que excluye la culpabilidad (en este sentido, García Pérez) mientras que otros autores opinan que constituye una causa de justificación, que excluye la antijuricidad.

Según algunos autores, el fundamento de la exención radica en la inexigibilidad de otra conducta que considera disculpable el encubrimiento a personas con las que el encubridor une una especial vinculación de familiaridad o de afectividad.

\section{REALIZACIÓN ARBITRARIA DEL PROPIO DERECHO (ART. 455)}

El art. 455 incrimina como delito la realización arbitraria del propio derecho, en los siguientes términos:

“1. El que, para realizar un derecho propio, actuando fuera de las vías legales, empleare violencia, intimidación o fuerza en las cosas, será castigado con la pena de multa de seis a doce meses.

2. Se impondrá la pena superior en grado si para la intimidación o violencia se hiciera uso de armas u objetos peligrosos".

Este delito castiga, en dos tipos (uno básico y otro agravado), al sujeto que, so pretexto de realizar o ejercer un derecho propio, se toma la justicia por su mano (González Rus). 
Miguel Polaino-Orts - Delitos contra la administración de justicia.

Una introducción a la regulación de algunas figuras en el Código Penal Español

Presupuesto del delito es la existencia de un derecho propio, que es ejercitado por el titular del mismo. Sujeto activo sólo puede ser quien, respecto del sujeto obligado, tiene y ejercita alguna pretensión jurídicamente válida y exigible (De La Mata Barranco): se trata, pues, de un delito especial, y no de un tipo común. Debe tratarse de un derecho propio, aunque no necesariamente individual, sino también compartido o colectivo.

Ejemplo de derecho individual: el caso paradigmático de realización arbitraria del propio derecho es el del cobro violento de un derecho de crédito: A debe mil euros a B. Éste, con la pretensión de que se los pague, acude a A y violentamente intenta cobrarse la deuda arrebatándole por la fuerza el dinero.

Ejemplo de derecho colectivo: A, molesto con que el bar de debajo de su casa impida dormir a todo el vecindario con el elevado ruido de la música, acude al local y violentamente intenta ejercer el derecho a la salud pública (que implica la ausencia de ruido desproporcionado).

El núcleo de la acción típica radica, precisamente, en el modo en que el titular del derecho lo ejercita: empleando medios violentos para ello. La filosofía que inspira el presente tipo es, pues, que el fin no justifica los medios: esto es, el ejercicio de un derecho no justifica el uso de medios violentos para conseguirlo.

La arbitrariedad del ejercicio del derecho proviene del carácter violento o intimidatorio del procedimiento empleado. La conducta compleja exige, de una parte: actuar fuera de las vías legales; y de otra, emplear violencia, intimidación o fuerza en la cosas:

- Actuar fuera de las vías legales menciona el quid de la cuestión. Esta expresión significa transitar caminos alternativos o diferentes a los legalmente admitidos en Derecho, esto es: seguir procedimientos ilegales no permitidos por el ordenamiento jurídico.

- Emplear violencia, intimidación o fuerza en las cosas alude al quomodo de la cuestión, es decir: al modo en que se ejercita o se pretende ejercitar el derecho en cuestión. Ha de hacerse usando medios ilegítimos en el ejercicio de un derecho, ya sea mediante medios físicos (violencia, fuerza) o psicológicos coactivos (intimidación).

Los medios violentos, intimidatorios o donde se emplee fuerza consistirán en actos que, en la mayoría de los casos, son incriminados como delitos (amenazas, 
Miguel Polaino-Orts - Delitos contra la administración de justicia. Una introducción a la regulación de algunas figuras en el Código Penal Español

coacciones, extorsión, robo con violencia o intimidación, incluso detención ilegal, etc.). Si esos actos son medios o procedimientos instrumentales al servicio del ejercicio del derecho propio, entonces no son sancionables como delitos autónomos, sino que se aplica el tipo del art. 455, que es lex specialis que tiene preferencia frente a los tipos autónomos. En cambio, si no se trata de medios o procedimientos instrumentales sino de actos delictivos cometidos al margen del ejercicio del derecho serán sancionables como delitos autónomos (v.gr., en caso de lesiones sobrevenidas, etc.).

Se trata de un tipo pluriofensivo que afecta más de un objeto de tutela: constituye una figura híbrida, a mitad de camino entre las coacciones y un tipo contra la Administración de Justicia. De hecho, sistemática y materialmente se halla más cerca de otras figuras delictivas contra la libertad o contra el patrimonio que de los delitos contra la Administración de Justicia. Desde este punto de vista, el delito del art. 455 supone un cuerpo extraño que desentona entre los demás delito contenidos en el título.

Para la consumación no se exige que el titular del derecho se salga con la suya y consiga alcanzar en la pretensión jurídica que integra su propio derecho. Basta con que, pretendiendo ejercer el derecho, emplee modos violentos o intimidatorios. Si el titular del derecho no ha comenzado aun a realizar actos de ejercicio del derecho pero sí ha empleado actos violentos o intimidatorios éstos serán sancionados como tentativa de realización arbitraria del propio derecho (si esos medios no constituyen otro delito) o como delito autónomo (si fueran subsumibles en otro tipo: amenazas, coacciones, etc.).

El art. 455.2 prevé un tipo agravado de realización arbitraria del propio derecho, que concurre cuando se empleen armas u objetos peligrosos en el ejercicio del derecho. La pena del tipo básico es de multa de seis a doce meses y la del tipo agravado en la superior en grado: esto es, multa de doce a dieciocho meses. El fundamento de la agravación radica en el mayor potencial lesivo que entraña la conducta del sujeto que hace uso de tales objetos contundentes, que crean una mayor peligrosidad $\mathrm{y}$, al tiempo, un debilitamiento o atemorizamiento mayor en la víctima (persona ante la cual se pretende ejercer la pretensión jurídica). 